\title{
DOUTRINA
}

\section{o Mandado de Segurança e o Direito Comparado}

ARNOLD WAID

L

JEMBRAVA GutTERIDGe, na conferêricia dos professôres de direito realizada em Cambridge, em julho de 1952, que o verdadeiro objetivo do direito comparado é menos a unificação do direito dos diversos Estados do que a melhor compreensão dos direitos nacionais pelo emprêgo do método comparativo, a descoberta da melhor norma de jure constituendo e a aproximação dos povòs. (1)

Na realidade, o constituinte de 1934, ao elaborar o novo instituto que era o mandado de segurança, não podia deixar de escrutar a história do direito pátrio e a "geografia do direito" que é, na feliz expressão do professor HAROLDO VALADÃo, o direito comparado.

Embora viesse à tona um instituto novo, profunda e tìpicamente brasileiro, que honra nossa cultura jurídica e nossa nacionalidade, um instituto sem correspondente exato em nenhuma outra legislação, teve o legislador que conhecer e aceitar o acervo da experiência dos outros povos que possuiram remédios processuais semelhantes ou parecidos.

Um dos problemas básicos do direito público tem sido, em todos os tempos, o do contrôle judicial dos atos administrativos. Um dos corolários do princípio da separação dos poderes é que a competência dos órgãos administrativos deve abranger tão sòmente a realização dos atos administrativos específicos, ficando a função judicante, em todos os seus aspectos, reservada aos tribunais. Assim, o Estado, representado por seus órgãos administrativos, se encontraria perante os tribunais na mesma posição que qualquer outra parte.

Diz Hans Kelsen que:

"Este ideal, que en cierta medida representa la concepción liberal del Estado, ha prevalecido en los derechos inglés y norteamericano durante un tiempo más largo que en los derechos del continente europeo, (especialmente los derechos francés y alemán); pero el ideal nunca se ha realizado completamente. En cada orden jurídico hay casos en que órganos distintos de los tribunales tienen que ejercitar funciones judiciales, estabelecer la existencia de um

(1) V. o relatório sôbre a Cambridge Conference of teacher of law in Revue de droit international et de droit comparé do Instituto Belga de Direito Comparado, Bruxelas, n.? 3-4, 1952, pp. 2i2-2i3. No mesmo sentido, FELIPE DE SClA CANIzARÉ, Iniciación al Derecho Comparado, Barcelona, 1954, p. 110 e seguintes. 
acto antijurídico y decretar la sanción estipulada por la ley. Especialmente las autoridades fiscales y policíacas son llamadas casi siempre $y$ en todas partes a desempeñar funciones judiciales o casi judiciales. Tan pronto como el orden jurídico autoriza a la administración pública a intervenir en forma más extensa con sus actos específicos en la vida económica y cultural, surge la tendencia a otorgar también a los órganos administrativos la función judicial que se encuentra orgánicamente conectada con la función administrativa específica. (2)

E' verdade que o contrôle judicial dos atos administrativos corresponde a uma concepção essencialmente democrática. Nos Estados autcritários, tal exame pelo judiciário não é admissível. O contencioso administrativo, que pcde, em certos casos, revestir o aspecto independente do Conselho de Estado francês, é então a técnica pela qual o próprio executivo se arroga o direito de examinar e julgar os seus atos. Na maioria dos casos, o contencioso administrativo não consegue alcançar uma verdadeira autonomia em relação aos outros corpos da administração e, assim sendo, pouca garantia oferece aos cidadãos lesados por atos administrativos. (3)

E' um exemplo sugestivo nesta matéria o que nos oferece o direito brasileiro já que "durante meio século aproximadamente, o conte:1cioso administrativo do Império não conseguiu sequer funcionar em regime de completa autonomia, isto é, sem interferência das autoridades da administração ativa. Tornando-se um anacronismo, foi repelido pelos republicanos de 1889 , ccmo se fôsse uim fantasma no meio dos Poderes do Estado". (4) Fantasma, poderíamos acrescentar, que dificultava sobremaneira a proteção dos direitos individuais que o constituinte republicano quis assegurar.

Uma defesa ampla dêsses direitos exige a existência de um contrôle realizado por órgãos totalmente independentes do Executivo. Coube à jurisprudência norte-americana desenvolver e hipertrofiar a tese da fiscalização dos atos do executivo e do legislativo pelo judiciário baseada na interpretação dos textos constitucionais. Numerosas obras focalizaram a importância da missão do poder judiciário nos Estados Unidos, referindo-se ao Government by judiciary, a The American doctrine of judicial supremacy, culminando tais estudos com a excelente e erudita monografia do comparatista EDOUARD LAMBERT, intitulada Le gouvernement des juges et la lutte contra la législation sociale aux Etats Un's (L'expérience américaine du controle judiciaire de la constitutionalité des lois). (5)

(2) HANS KELsEn, Teoria general del Derecho y del Estado, trad. de Eduardo GARCia MAYNES, México, Imprenta Universitáris, 1950, p. 290 e seg.

(3) Sôbre o contencioso administrativo no Brasil, v. J. GuILHERME DE ARAGÃo A Justiça administrativa no Brasil, publicação da Fundação Getúlio Vargas, 1955, p. 4 do mesmo autor, La Jurisdiction administrative au Brésil, Rio de Janeiro, Imprensa Nacional, 1955, p. 13 e seg.

(4) J. GuIl herme de ARAgão, A justiça administrativa no Brasil, p. 4.

(5) EdOUARD LAMBERT, Le gouvernement des juges et la lutte contra la législation scciale aux Etats-Unis, Paris, Marcel Giard \& Cie., 1921. 
O judicial review fêz com que, desde a decisão do Chief Justice M. MaRSHALL, no caso Marbury v. Madison, em 1803, os tribunais norte-americanos não se limitassem a aplicar a lei mas indagassem da sua constitucionalidade. Assim sendo, o papel da lei para o jurista não é o mesmo nos Estados Unidos e no velho mundo. Na palavra de COURTENAY ILBERT, o jurista americano concebe as legislaturas como corpos cuja atividade deve ser controlada e é efetivamente controlada pelas côrtes. A lei é assim "freinée par un réseau subtil de limitations constitutionnelles", (6) existindo sempre o risco de ser ou não acatada pela jurisprudência.

Este risco que a lei corre é também sentido entre nós, no Brasil, e quando o legislador elabora normas sôbre a entrada de bagagens e de mercadorias do exterior, quando regula o pagamento do impôsto de cessão ou do impôsto do lucro imobiliário, êle pode prever que alguns artigos serão considerados inconstitucionais pelo judiciário, "não por ferir ostensivamente a letra da constituição, mas por uma interpretação ampla que o juiz fará do espírito e da intenção da lei, da mens legis.

Nos Estados Unidos, a Suprema Côrte foi o baluarte da proteção dos direitos individuais inclusive contra as reformas sociais e a socialização do direito pretendidas pelo New Deal. Quando se travou, em 1938, a luta entre o executivo e o judiciário é que êste perdeu o seu predomínio permitindo que os autores assinalassem o fim do govêrno dos juízes.

Tôda a evolução da política social norte-americana está ligada à atuação do judiciário. Assim é que ROGER PINTo, professor na Faculdade de Direito de Lille, ponderou que:

"Au moment ou l'économie et la philosophie individualistes nées des mouvements commerciaux du XVIIIe siècle, se trouvent modifiées et dépassées par une économie et une philosophie sociales nouvelles, avènement rendu nécessaire par la révolution industrielle et le développement du machinisme, au moment donc bu la société américaine essaie de contrôler ces forces par une législation appropriée, le rôle du juge, gardien éclairé ou étroit d'une constitution vieillie, passe au premier plan". (7)

No mesmo sentido é a afirmação de W. Y. Elliot que encarece a necessidade de adaptar a constituição às novas necessidades sociais para que seja a expressão de uma justiça viva. Assevera Elliot que "quand, par exemple, des garanties procédurales constitutionnelles des droits des citoyens, que ccnvenaient pour protéger la liberté individuelle contre les persécutions pcilitiques arbitraires dans les communautés agraires, sont employées comme des instruments rigides pour faire échec à des méthodes de police moderne dans les grandes communautés métropolitaines, on aboutit, en ossifiant sinsi les vieilles règles, à détruire la Constitution véritable". (8)

(6) LAMBERT, ob cit. p. 19.

(7) ROGER PINTO, Eléments de droit constitutionel, Lille, 1948 p. 237.

(8) Ap. Edouard Lambert et J. R. XIRAU, L'ancêtre americain du droit comparé - La doctrine du juge Story, Paris, Sirey, 1947, p. 298. 
$\mathrm{Na}$ realidade, tanto nos Estados Unidos como no Brasil, as medidas judiciais foram empregadas contra a administração pública a fim de evitar a aplicação de certas medidas necessárias para garantir o bem-estar social. Já se disse que o progresso se realizou proporcionalmente à limitação do campo de aplicação dos interditos possessórios que, em nosso direito, foram empregados para proteger centros de jôgo, evitar inspeções sanitárias etc... Tanto nos Estados Unidos quanto no Brasil, o poder judiciário na sua preocupação de proteger os intangíveis direitos individuais tem desprezado, em alguns casos, interêsses sociais. Tal atitude é natural já que o judiciário constitui a única proteção que o cidadão pode ter numa época de socialização do direito.

Devemos salientar todavia que nos Estados Unidos o judiciário desempenha uma missão mais importante na evolução da vida política do país porque a formação dos juristas se fêz menos pelo estudo das leis (statute) do que pelo case-system ou seja pelo exame da jurisprudência já que apenas uma pequena parcela do direito está codificada. (9)

A luta da Suprema Côrte contra a legislação social não obedeceu, por outro lado, a um movimento uniforme e já em 1904, no caso Lochner v. New York, em que se discutiu a primeira lei que limitava a duração do trabalho e cuja inconstitucionalidade foi reconhecida pelo tribunal, o justice Holmes, em voto vencido, assinalava que há uma série de restrições à liberdade individual impostas pelo bem-estar comum e que todos devem acatar por responderem a imperativos de ordem social.

Atualmente, mesmo nos Estados Unidos, o judiciário está perdendo a sua prepotência. Por maior que tenha sido o seu poder, jamais houve na realidade o govêrno dos juízes porque êstes podiam deixar de aplicar uma decisão mas nunca tiveram competência para decidir. "Ils contrôlent mais ne gouvernent pas". (10) Hoje, quando os constitucionalistas estudam $L a$ fin du principe de Séparation des pouvoir, (11) podemos com a maioria dos publicistas reconhecer que a hipertrofia do executivo relegou o, judiciário a um plano secundário embora ainda seja o grande esteio protetor dos direitos individuais. (12)

Não é pois estranho que o sistema americano nos ofereça remédios correspondentes ao nosso mandado para evitar a aplicação de normas inconstitucionais.

Deixando de lado o habeas-corpus, os writs mais importantes são mandamus, injunction, prohibition, quo warranto e certiorari. É preciso salientar que o

(9) San Tiago Dantas, A Educaçäo Jurídica o a Crise Brasileira, S. Paulo, Emp. Gráf. da Revista dos Tribunais, p. 17 e seg.

(10) MAURice DUVERger, Les régimes politiques, Paris, Presses Universitaires, 1948, p. 90 .

(11) MARcel De la Bigne Villeneuve, La fin du principe de séparation des pouvoirs, Paris, Sirey, 1934.

(12) V. ARNOLD WALD, A evolução do direito e a absorção da administração privada pela administração pública, Imprensa Nacional, 1953, p. 16. 
mandamus e a injunction não são remédios específicos contra atos do poder público, admitindo-se a uma utilização contra atos de particulares. (13)

Os writs são remédios típicos, assinalando a doutrina norte-americana que

"Where the party has an adequate remedy by action, the writ will not be awarded".

O mandamus é uma ordem do tribunal que visa a compelir alguém a exercer certo dever de ofício, restaurando o direito lesado. Cabe para exigir o cumprimento de um dever legal. E graças a êle que a parte obtém certas licenças ou certiłões a que tem direito e que a administração the nega.

Esta medida não é concedida normalmente contra o Presidente da República nem contra o legislativo. Os tribunais também não ordenam às autoridades administrativas a prática de atos que, embora constituam dever legal, teriam consequiências manifestamente contrárias ao interêsse público. (14) GELLHORN cita, a propósito, o "caso de writ de mandamus que foi denegado pelo tribunal por ser impetrado contra o ato de uma junta eleitoral que se recusara a fazer o registro de certos candidatos à pena de prisão. A junta não aceitou as referidas candidaturas tendo em vista que, se eleitos, os candidatos não poderiam exercer o mandato por estarem cumprindo pena. Embora não houvesse lei que autorizasse a denegação do registro, o writ não foi concedido atendendo o tribunal a inutilidade de tal eleição. (15)

Havendo controvérsia quanto à matéria de fato, é normalmente ouvida a parte interessada. Quando a questão discutida se limita ao direito, a ordem pode ser expedida liminarmente.

Enquanto no mandamus exige-se um facere, na injunction exige-se uma abstenção.

Neste sentido é a lição de OSCAR RABASA: "E1 writ of mandamus, ordenamiento judicial, es el procedimiento que desempeña la misma función que el writ of injunction, con la sola distinción de que en tanto que este ultimo sirve para "impedir", en forma prohibitiva, la ejecución del acto o ley reclamados, el primero tiene por objecto la "ejecución", de un modo activo, de un acto o obligación por la autcridad demandada quando la violacion consiste en la negativa de esta a ejecutar lo que legalmente esta obligada a llevar a cabo. De modo que el injunction es de efecto negativo pues impide que la autoridad viole la ley por un acto de comisión; el mandamus es de resultado positivo ya que compele a la autoridad a que ejecute su obligación y no viole la ley por una omisión. Ambos recursos, pues, desempeñan sepa-

(13) WAlter Gellhorn, Administrative Law-Cases and Comments, The Foundation Pres Inc. Chicago, 1940 p. 794. CASTRo NUNES na sua obra - Do Mandado de Segurança - Revista Forense, $5 .^{2}$ ed., p. 63 , limita o campo de aplicação da injunction à esfera administrativa.

(14) A respeito do mandamus, $\nabla$. o trabalho do Dr. CALly Silva, pesquisador do Centro de Pesquisas da Casa de Rui Barbosa sôbre êste tema, a ser publicado no livio em preparo - $O$ mandado de segurença é a sua jurisprudência.

(15) Gellhorn, ob cit. p. 850. 
radamente las dos funciones essenciales que en el sistema mexicano realiza el juicio de amparo, dentro de un solo procedimiento". (16)

A injunction filia-se històricamente aos interditos embora o processo da injunction se diferencie do dos interditos. (17) A injunction é uma arma mais efetiva do que os interditos, abrangendo o seu canipo de aplicação todo o direito, especialmente no tocante aos direitos de família, à proteção da propriedade, ao cumprimento das obrigações contratuais e ao ressarcimento dos danos causados.

A injunction foi uma criação da equity, distinguindo-se as mandatory injunctions que ordenavam a realização de um ato das restrictive injunctions que proibiam a realização do ato. Originàriamente a injunction teve caráter proibitivo e hoje a mandatory injunction se confunde em certo sentido com o writ of mandamus. Certas injunctions foram inclusive concedidas a fim de impedir a execução de sentenças lavradas pelos tribunais de acôrdo com o common law. (18) A desobediência a uma injunction importa no crime de contempt of Court, espécie de crime de responsabilidade por desobediência à ordem do tribunal, que pode importar para o infrator na aplicação de pena de prisão ou de multa.

A injunction que foi inicialmente o apanágio dos tribunais de equity, passou a ser concedida, a partir de 1854 , pelas côrtes de Common Law.

A injunction é hoje utilizada, conjuntamente com a ação de trespass no direito anglo-americano, a fim de proteger o direito do possuidor. Pode outrossim assegurar a execução de uma obrigação de fazer ou não fazer. O tribunal pode obrigar o devedor a cumprir a obrigação assumida que no caso não se resolverá em perdas e danos. Assim é possivel obter pela injunction uma specific performance da obrigação.

A injunction pode ser provisória, correspondendo à nossa medida liminar e à einstweilige Verfügúungen do direito alemão, e neste caso é denominada interlocutory. Serve como medida conservatória a fim de evitar prejuizo irreparável. Embora geralmente proibitiva, mandando cessar a prática de um ato ilegal, pode também implicar a prática de um ato para, por exemplo, restituir ao lesado o statu quo anterior ao ato ilegal e lesivo. Tanto o direito inglês, como o norte-americano, admitem a caução no caso de concessão da medida liminar. A injunction perpetual ou definitiva é concedida no fim do julgamento, podendo ser submetida a determinada condição.

A injunction desempenha um papel tão importante no direito anglosaxão que nos revela como um instituto processual pode modificar a própria estrutura do direito substantivo e, em particular, o direito das obrigações. PHANOR J. EDER, professor da New York State University, lembra que tendo

(16) OSCAR RABASA, El derecho anglo-americano, p. 641.

(17) W. Buckland \& ARNold mac NaIR, Roman law and Common law, 2 a $^{\mathrm{a}}$ ed. revista pelo Professor Lawson, Cambridge University Press, 1952, p. 420 e seguintes, fazem a análise das relsções entre a injunction e os interditos.

(18) ARminjon Nöne et Wolff, Traité de Droit Comparé Paris Libraire générale de Droit et de Jurisprudence 1950 vol. II p. 514. 
BetTe Davis um contrato exclusivo com a Warner Brother até 1942, decidira ela rompê-lo em 1937, fazendo outro com uma companhia inglêsa. O tribunal britânico, a pedido da Warner, concedeu uma injunction para que a atriz atendesse ao aspecto negativo do contrato, não trabalhando para outrem, sendo rejeitada a defesa do advogado de BETTE DAvIS, que considerava o contrato como uma escravidão embora fôssem de ouro as algemas. (19)

A injunction se aplica pois tanto no domínio dos conflitos de vizinhança que no campo contratual e delitual. "Comme en matière de contrats, l'injunction est en matière de torts une mesure exceptionnelle (Shelfer versus City of London Electric Lighting Co. 1.895). Elle laisse intacte l'action en dommages-intérêts qui sanctionne normalement le dommage infligé par un tort: le tribunal reste libre d'accorder des dommages "pour compléter l'injunction ou en tenir lieu" (Lord Cairn's Act, 21 et 22 Vict. c. 27, s. 2). Cette règle a été inscrite dans le Supreme Court of Judicature Act, 1925, 15 et 16 . Geo, 5 , c. 49 , s. 37 ", (20)

No direito norte-«mericano, a injunction tem sido um meio de interferência do judiciário nos dissídios trabalhistas. Até o Norris-La Guardia AntiInjunction Act, de 1932, os tribunais usaram amplamente o remédio processual para evitar as greves, as manifestações de grevistas etc... alegando que assim estavam protegendo a propriedade privada e a paz pública. OGG \& RAY esclarecem a respeito que "the writ of injunction originated far back in English judicial history, without reference, of course, to modern industrial situation. But its use in this country in later days has been principally in connection with labor disputes..." (21) Em 1946, o govêrno dos Estados Unidos obteve uma injunction contra JOHN L. LEWIS e o sindicato dos mineiros a fim de que lhes fôsse proibido entrar em greve sob pena de "contempt of court". Declarada a greve, não obstante a injunction, o sindicato e o seu presidente foram condenados a pagar uma multa de US\$ $3.500 .000,00$, entendendo o tribunal que a lei Norris-La Guardia já citada não se aplicava aos casos em que fôsse parte o govêrno dos Estados Unidos. (22) Vimos assim sumàriamente o papel desempenhado pela injunction que se, de um lado, se aproxima do nosso mandado de segurança não deixa de ter, por outro, certa relação com os interditos possessórios e a ação cominatória.

O writ of prohibition visa evitar que tribunais ou órgãos administrativos de competência restrita conheçam de matéria que não esteja nas suas atribuições legais.

O writ quo warranto assegura o direito a um título ou ao exercício de uma função. Recentemente, no Estado de Dakota do Norte, foi por um writ quo warranto que se decidiu quem devia exercer o cargo de governador do

(19) Phannor J. Eder, A comparative survey of Anglo-American and Latin-American Law, New York University Press, 1950, p. 81.

(20) Arminjon, Nolde et WolfF, ob. cit., vol. III, Paris, 1952, p. 181.

(21) FREDERIC A. OGg and P. ORMAN RAY, Introduction to American Government, 9. ${ }^{\text {a }}$ ed. New York Appleton Century Crofts Inc., 1948, p. 731.

(22) OGG and RAY, ob. cit. p. 732, nota 1. 
Estado. Tendo sido o governador LANGER condenado a uma pena de detenção por um tribunal federal, o vice-governador OLson tomou posse do cargo. LANGER entrou com um pedido de quo warranto a fim que lhe fôsse assegurada a continuação do exercício do cargo. Tomando conhecimento do caso a Suprema Côrte de Dakota do Norte rejeitou o writ confirmando no cargo o vice-governador já empossado. Um outro writ da mesma natureza foi acolhido pela mencionada côrte contra o governador MoODIE que não residira durante cinco anos antes da eleição no referido Estado como o exigia a constituição estadual.

O writ of certiorari provoca a verificação pelos tribunais da legalidade do ato administrativo, funcionando como recurso judicial das decisões dos funcionários ou corpos administrativos como também de decisões judiciárias. O recurso sòmente é admitido em casos de dúvida, conferindo-se, através dêle, à Suprema Côrte a supervisão das decisões para assegurar a uniformidade e evitar a diversidade de julgados que poderiam prevalecer nos diversos circuitos. E' um recurso unificador e construtivo, pelo qual não se revê o mérito da questão, limitando-se o tribunal à revisão e reparação dos erros de direito, sem levar em consideração a prova de fato. Numerosos são os certiorari julgados pela Suprema Côrte, a maioria dos quais são denegados, o que se explica por não haver recurso no caso da decisão administrativa evidentemente ilegal considerada inválida pelos tribunais inferiores. (23)

Nenhum dos writs norte-americanos se confunde com o nosso mandado de segurança que realiza simultâneamente as funções de todos êles, obrigando ou impedindo as autoridades administrativas de realizar certo ato, assegu. rando a determinado funcionário o exercício do seu cargo, reconhecendo num caso concreto a inconstitucionalidade de uma lei ou a ilegalidade de uma decisão administrativa ou judiciária.

Vimos assim que, como o asseverou Themistocles Cavalcantr, "não são poucas as afinidades do instituto americano com o nosso mandado de segurança" (24) já que os writs são os meios de proteção do direito indiscutivel na falta de outros recursos adequados.

O constituinte de 1934 não pôde deixar de receber e utilizar o acervo da experiência constitucional e administrativa dos Estados Unidos quando introduziu o mandado de segurança na nossa constituição.

Outra lição, porém, mais próxima exerceu influência mais direta sôbre a criação do instituto brasileiro. Trata-se do recurso de amparo oriundo do direito mexicano.

O amparo surgiu em 1843 na constituição estadual do Yucatán por proposta do deputado MANUEL C. REJón, garantindo-se então, pelo mencionado recurso, a proteção rápida e eficiente dos interêsses individuais contra os atos de autoridades administrativas que lhes causassem prejuízos. O juicio de amparo surgiu inicialmente como meio de assegurar os direitos e garantias

(23) ARTHUR T. VANDERBLIT, The doctrine of the separation of prowers and ists presente-day significance, The University of Nebraska Press, 1953, p. 133.

(24) Themistocles Brandão Cavalcanti, do Mandado de Segurança, Rio de Janeiro, 1934, p. 19. 
individuais garantidos pelo texto constitucional. Efetivamente, a Constituiçäo do Estado de Yucatán estabelecia no seu art. 63 que cab:a à autoridade judicial "amparar en el goce de sus derechos a los que le pidan su proteción... limitando-se a reparar el agravio en la parte en que la constitución hay sido viclada".

Discutiu-se muito as origens remotas do recurso de amparo que alguns zutores quiseram encontrar nos Cuatro Procesos Forales de Aragón de 1772 que se referem à concessão de "amparos en defensa del Rey, de las leyes y de los Reynícolas". Na realidade sòmente a terminolog:a do amparo tem as suas origens no documento espanhol do século XVIII. Por uma tradiçãc, muito comum em matéria jurídica, o legislador mexicano conservou o nome de um antigo instituto para com êle criar um remédio processual novo.

Em 1847, por ocasião da reforma constitucional, estabeleceu-se que os tribunais da federação dariam o recurso de amparo a qualquer domiciliado na República para exercer e conservar os direitcs garantidos pela Constituição e pelas leis constitucionais contra tôda violação por parte das autoridades federais ou estaduais, executivas ou legislativas. Os tribunais, de acôrdo com a referida reforma constitucional, devem conceder a sua proteção no caso particular è concreto que lhes é apresentado sem fazer nenhuma declaração de caráter geral sôbre a constitucional:dade da lei ou do atọ impugnado.

O instituto conservou a mesma fe:ção na Constituição Federal de 1857 e na vigente elaborada em 1917 e reformada em 1950. E' o seguinte o texto legal vigente que encontramos no art. 103 da carta magna mexicana:

"Los Tribunales de la Federación resolverán tôda controversia que se suscite: duales.

I - Por leyes o actos de la autoridad que viole las garantias indivi-

II - Por leyes o actos de la autoridad federal que vulneren ou restrinjan la soberania de lcs Estados.

III - Por leyes o actos de las autoridades de éstos que invadam la esfera de la autoridad federal".

Vemos assim que o amparo é o remédio processual cabível sempre que há uma lesão a direitos individuais garantidos seja pela Constituição, seja por leis ordinárias. Um dos grandes marcos na evolução do instituto foi de passar de defensor do homem no plano constitucional a remédio utilizado para garantir ta:s direitos na esfera da legalidade. Desempenha ainda outro papel a fim de delimitar exatamente as competências respectivas da União e dos Estados.

O art. 107 da Constituição citada estabelece grosso modo o rito processual do amparo, esclarecendo que:

"Todas las controversias de que habla el artículo 103 se seguirán a instancia de la parte agraviada, por medio de procedimentos e formas del orden jurídico que determinará una ley que se ajustará a las bases seguintes:

I. La sentencia será siempre tal, que solo se ocupe de individuos particulares, limitandose a ampararlos e protegerlos en el caso especial sobre 
el que verse la queja, sin hacer una declaración general respecto de la ley o acto que la motivare".

E' prec so assinalar, com os autores mexicanos, que o amparo, recurso individual no caso de lesão de direito por autoridades públicas, tem sido utilizado preponderantemente como proteção dos direitos do homem, ficando relegada a um plano secundário a sua função constitucional de demarcador das competências dos Estados e da União.

O campo de aplicação do juicio de amparo é mais amplo do que o mandado de segurança, pois aquêle abrange o domínio que, entre nós, é reservado ao habeas-corpus. Do amparo, já se disse que:

"No hay una institución política más grata ni de más arraigo para el pueblo que el juicio de amparo, por el cual, en el curso de ciento nueve años que lleva de vigencia, se le ha protegido contra la arbitrariedad: por el se ha salvado la vida a gente condenada sin procesos defectuosos; han recuperado 1a libertad quienes arbitrariamente sufriam prisiones injustas; se ha liberado de servicios forzados de las armas o trabajos publicos a quienes sin su voluntad o sin que se cumpliran los requisitos legales, eran llevados a ejecutarlos; se han defendido hogares; se ha garantizado la libertad de pensamiento; se han evitado confiscaciones, etc...." (25)

Quem deve impetrar o amparo é o próprio lesado mas permite a lei que outras pessoas o façam quando a própria índole da violação impede que o prejudicado reccrra à justiça como em certos casos em que a vítima da arbitrariedade administrativa está privada da liberdade ou ameaçada de perder a vida.

C) processo do amparo se assemelha ao do nosso mandado. Começa com e. petição do impetrante em que deve assinalar a lesão de direito e a autoridade responsável. Diante do pedido, o juiz pede informações ao coator e dá vistir dos autcs ao Ministério Público. Ne audiência, o impetrante e a administração pública apresentam as suas provas e o juiz dá a sua sentença, da quai cabe recurso para os tribunais superiores.

O juiz, de acôrdo com a legislação mexicana, pode conceder a medida liminar, ou seja suspender os efeitos da violação até que decida sôbre o fundo da questão, sempre que houver perigo de dano irreparável. Quando a concessão da liminar puder causar danos a terceiros, o impetrante deverá depositar uma caução.

Por outro lado, determinando o art. 14 da constituição que as sentenças sejam sempre proferidas de acôrdo com a lei, o amparo é utilizado como recurso contra as decisões fina:s dos magistrados que estiverem em choque com o texto legal, funcionando assim como uma espécie de cassação.

O amparo rão existe sòmente no México mas em diversas repúblicas da América Central como E1 Salvador, Nicarágua, Honduras e Guatemala, tendo também sido introduzido na Constituição Espanhola de 1931. Esta assegu-

(25) German Fernandez del CAStillo, El amparo como derecho del hombre en la Declaración Universal, in "Boletin del Instituto de Derecho Comparado de México", n. ${ }^{\circ} 27$, setembro-dezembro de 1956 , p. 10. 
rava no seu art. 101 recursos contra a ilegalidade dos atos da administração por excesso ou desvio de poderes, especificando em artigo seguinte que seriam organizados tribunais especiais para efetivar o amparo das garantias individuais. Infelizmente a experiência jurídica do amparo na Espanha se limitou ao período republicano em que a agitação não permitiu o completo desenvolvimento do instituto.

Na IX Conferência Internacional Americana, reunida em Bogotá, em 1948, a delegação mexicana propôs que fôsse incluído na Declaração Americana de Direitos e Deveres do Homem um artigo que assegurasse a proteção eficiente e rápida dos direitos individuais contra os atos da administração pública. Assim foi incorporado à Declaração o art. XVIII de acôrdo com o qual

"Toda persona puede ocurrir a los Tribunales para hacer valer sus derechos. Asímismo, debe disponer de un procedimiento sencillo y breve por el cual la Justicia lo ampare contra actos de la autoridad que violen, en perjuicio suyo, algunos de los derechos fundamentales consagrados constitucionalmente".

No mesmo ano, a Assembléia Geral das Nações Unidas incluiu na Declaração Universal dos Direitos do Homem o art. $8 .^{\circ}$ do conteúdo análogo e de acôrdo com o qual:

"Todo homem tem direito a receber dos tribunais nacionais competentes remédio efetivo para os atos que violem os direitos fundamentais que the sejam reconhecidos pela constituição ou pela lei".

A estrutura real do amparo não tem sido muito bem compreendida pelos juristas brasileiros que o estudaram. THemistocles CavalCantr, interpretando a lição de IGNACio VALLARTA, afirma que o amparo não é um recurso comum. "Não tem por fim corrigir injustiças, mas apenas prevenir as infrações da Constituição". (26) Não há dúvida que o amparo não seja um remédio de equiidade; protege, ccmo o nosso mandado de segurança, direitos certos e líquidos. Mas não é indispensável que o direito seja assegurado pela Constituição. Basta que tenha a proteção legal. Inicialmente o amparo surgiu como remédio destinado a assegurar direitos constitucionalmente reconhecidos. Hoje protege o indivíduo contra tôda lei inconstitucional e contra todo ato administrativo ilegal. Já assinalamos esta evolução que o instituto sofreu sob a pessoa das necessidades sociais.

CASTRO NUNES faz interessante análise do instituto mexicano, esclarecendo que: "é inexato identificar o nosso mandado de segurança com o amparo mexicano. Êste tem as suas raízes históricas na fuero de manifestación, misto de interdito e de habeas-corpus que visava principalmente a ação exorbitante dos juízes e dos particulares, nos atentados às pessoas e aos bens. Com êsse caráter passou para o México e outras repúblicas de origem ibérica, que, como São Salvador, o imitaram. O amparo mexicano é remédio contra sentenças e procedimentos judiciais principalmente, e só, em segundo plano,

(26) Themistocles BRandão Cavalcanti, ob. cit. p. 23. 
"contra atos de autoridades distintas da judicial". (27) Quem lê a lição de CASTRO NUNES poderá acreditar que no direito mexicano o amparo caiba contra atos de particulares, o que não corresponde à verdade.

O que existe de fato são duas funções distintas do recurso de amparo que é um remédio contra atos arbitrários do executivo e do legislativo e, por outro lado, um recurso das sentenças que infringem textos legais; nunca, todavia, cabe contra atos de particulares. (28)

Diferente do recurso de amparo por se limitar a proteger os direitos constitucionalmente garantidos é o remédio processual que encontrávamos no art. 144 da Constituição Austríaca de 1920. Tal recurso era utilizado havendo "un intérêt privé suffisament individualisé ao respect d'une disposition objetive de la Constitution". (29)

O processo na legislação austríaca era sumário, importando na anulação do ato administrativo ou da lei increpados de inconstitucionais.

Projetos de institutos análogos ao nosso mandado de segurança e visando a obstar a prática de ato administrativo ilegal existem também na Argentina e no Uruguai. (30)

Já tivemos o ensejo de ver que os países de contencioso administrativo não admitiram o contrôle judiciário dos atos da administração pública, considerando a função fiscalizadora exercida pelo magistrado contrária ao princípio da separação dos poderes. A questão não deixa de estar ligada ao problema do contrôle da constitucionalidade das leis, através do qual o judiciário pode apreciar os atos de legislativo e do executivo. É interessante ressaltar que eminentes constitucionalistas franceses como LÉON DUGUIT e MAURICE HAURIOU defenderam a introdução de tal contrôle na França, considerando-o a maior garantia da manutenção da legalidade e da realização do estado de direito embora em sentido contrário se manifestassem comparatistas do porte de EDOUARD LAMBERT. (31)

$\mathrm{Na}$ realidade, o contencioso administrativo francês deu sérias garantias ao indivíduo contra os excessos da administração, inclusive com a elaboração de doutrinas novas como a da responsabilidade baseada na culpa de serviço

(27) Castro Nunes, Do mandado de segurança, Rio de Janeiro, Ed. da Revista Forense, 5. ${ }^{\mathrm{a}}$ ed. 1956 , p. 59 , n. ${ }^{\circ} 18$.

(28) Sôbre o amparo, v. Germán Fernandez del Castillo, art. cit., Ignacio L. Vallarta, El Juicio de Amparo y el Writ of Habeas-Corpus, México, 1881, Ignacio Burgoa, E1 juicio de Amparo, 1951 e Romeo Leon Orantes, El juicio de Amparo, México, 1941

(29) V. Charles Eisenmann, La justice constitutionelle de PAutriche, Paris, 1928 e B. Mirkine-Guetzevitch, Modernas tendências del derecho constitucional, trad. de Sabino Alvarez Gendin, Madrid, Editorial Reus, 1934, p. 31 e seg.

(30) CASTRo NUNES, ob. cit. p. 61 , faz referência eos projetos apresentados por BIElsa na Argentina e Couture no Uruguai.

(31) LÉon Duguit, Leçons de Droit Public Général, Paris, E. de Bocard, 1926, p. 288 e seg. e EDOUARd LAMBERT, Le gouvernement des juges já cit. p. 4 e seg.

(32) Marcel Waline, Traité élémentaire de droit administratif, 5. ${ }^{\mathrm{a}}$ ed. Paris, Recueil Sirey, 1950, p. 550 e seg. e LÉon Dugurt, ob. cit. p. 310 e seg. 
cu no dever de garantia. (32) O sistema empregado já é, todavia, totalmente diferente do ncsso e o seu sucesso se explica talvez menos pela boa técnica do instituto do que pela sabedoria, senso de equilíbrio e profunda autonomia dos membros do Conselho de Estado. (33)

O Conselho de Estado decide soberanamente os recursos em matéria de contencioso administrativo e os pedidos de anulação de atos administrativos quando houve excesso de poder. Os recursos de anulação por excesso de poder têm como fundamento a incompetência do funcionário, a existência do vício de forma, a falta de justa causa ou o desvio do poder. (34) E a teoria do détournement de pouvoir que mais nos interessa por ser de aplicação generalizada e constituir uma conquista da teoria geral do direito. Há desvio de poder quando o funcionário pratica um ato de incontestável legalidade quanto à sua forma, competência e conteúdo, mas atendendo a motivo estranho ou diverso daquele pelo qual o legislador the atribui a faculdade de praticar o ato.

Criaçãc, jurisprudencial de destacado valor reṕresenta a tecria do desvio do poder, no campo do direito público, o que o abuso do direito foi na esfera privatista.

"La recherche du détournement de pouvoir - escreve MARCEL WALINE, de la part de la jurisprudence, une certaine hardiesse puisqu'il s'agit en somme de découvrir l'esprit de la législation et de sanctionner des violations de l'esprit, non de la lettre des lois". (35)

Não fol sem razão que os autores franceses puderam ter orguiho da doutrina elaborada pelo Conselho de Estado, sendo unânimes em the fazer os maiores elogios.

LOUIS JOSSERAND a considera "le chef-d'cuvre de notre Conseil d'État, la plus harmonieuse construction juridique qu'il ait érigée dans la plénitude de sa juridiction souveraine". (36) MAURICE HAURIOU conceitua, por sua vez, a teoria do détournement de pouvoir como "un jaillissement de directives". (37)

No Brasil, o mandado de segurança tem sido o remédio processual proteiforme que corresponde ao mesmo tempo ao mandamus e à injunction, ao certiorari e ac quo warranto, sempre que concebidos como recursos judiciários contra atos administrativos, desempenhando ainda papel análogo ao direito

(33) H. Berthélemy, Traité élémentaire de droit administratif, $11 .^{\mathrm{a}} \mathrm{ed}$. Paris, Rousseau \& Cie., Editeurs, 1926. p. 1.101.

(34) Marcel Waline, ob. cit. p. 124.

(35) Marcel Waline ob. cit. p. 132. No mesmo sentido, H. Berthélemy, ob. cit̂́. p. 1131.

(36) Louis JosSERAND, De l'esprit des droits et de leur relativité, 2. a ed. Paris. 1939 , p. 257 e seg. V. também sôbre o mesmo assunto, o trabalho dêste autor, Les mobiles dans les actes juridiques de droit privé, Paris, Dalloz, 1928, p. 137 e seguintes.

(37) Maurice Hauriou, Précis de drcit administretif, II ed., p. 417 e seg. V. também a respeito LÉon DUGUIT, cb. cit. p. 280. 
mexicano, com as restrições oriundas da defesa da liberdade de locomoção reservada ao habeas-corpus.

Sucessor dos interditos possessórios e do habeas-corpus hipertrofiado pela nossa jurisprudência, constitui o mandado o instrumento adequado para corrigir as ilegalidades e os abusos cometidos pelos órgãos estatais, ou por particulares no exercícic de funções delegadas pelo poder público.

A teoria francesa do détournement de pouvoir tem sido admitida entre nós embora com outra fisionomia diante da dificuldade de apurar tal desvio no rito especial do mandado. Assim mesmo, a nossa doutrina a consagrou ao exigir que o ato, para ter autoridade de govêrno, "esteja em conformidade com a lei ou tenha sido determinado por motivos legítimos, isto é, por motivos que a lei estabeleça como pressupostos do ato". (38)

A jurisprudência brasileira tem admitido a concessão do mandado de segurança quando o ato praticado pela administração pública, embora sendo legal, disfarça evidente desvio ou abusi de poder. Assim, no mandado impetrado pela Emprêsa de Transportes Potiguar contra as autoridades locais, que se recusavam a permitir o tráfego dos carros da impetrante em certo horário, a fim de favorecer emprêsa concorrente, o tribunal de justiça do Rio Grande do Norte concedeu a medida requerida por ter verificado a existência de um abuso de direito por parte do impetrado. (39)

Vimo: assim os antecedentes históricos do instituto e os seus correspondentes no direito estrangeiro, que tiveram de esclarecer a nossa jurisprudência, gu:ando-a nos meandros pelos quais o mandado de segurança foi abrindo uma estrada vasta e ampla para a proteção dos direitos individuais. Podemos agora defin:r o instituto e analisar a sua índole para depois vermos a extensão que tomou.

O mandado de segurança é pois o recurso judicial pelo qual o lesado pede ao juiz que proíba ou ordene a prática de certo ato por parte dos órgãos estatais ou de seus delegados. O mandado "previne a ilegalidade, faz cessar a violação, obsta a que continue a lesãc", (40) modifica uma situação ilegal ou abusiva não comportando todavia a reparação pecuniária do prejuízo causado que deverá ser pleiteado em ação ordinária. Em síntese, o mandado de segurança defende os direitos individuais não protegidos pelo habeas-corpus contra os atos ilegais dos poderes públicos.

(38) FRANCISCO CAMPOS, Direito administrativo, pp. 86-88. V. tzmbém o excelente voto do Ministro Philader r r Az Azevedo no recurso Extraordinário n. ${ }^{\circ} 8.575$, in Um triênio de judicatura, S. Paulo, Max Limonad, vol. VII, pp. 170 a 212 e especialmente pp. 202-203.

(39) V. Revista de Direito Administrativo, vol. XIV, outubro-dezembro de 1948 , p. 52 ○ seg.

(40) Castro Nunes, cb. cit, 2. a ed, p. 53. 